\title{
Analysis of cases of infections associated with health care registered in Constanta County during 2014-2018
}

\author{
Analiza cazurilor de infecţii asociate asistenţei medicale inregistrate în judeţul \\ Constanţa în perioada 2014-2018
} \author{
Sorin RUGINĂ $\breve{1}^{1,2,3,4}$ \\ ${ }^{1}$ Școala Doctorală de Medicină, Universitatea „Ovidius“, Constanța, România \\ ${ }^{2}$ Facultatea de Medicină, Universitatea „Ovidius“, Constanța, România \\ ${ }^{3}$ Academia de Științe Medicale, România \\ ${ }^{4}$ Academia Oamenilor de Știință, România
}

Corina VOINEA ${ }^{1}$, Elena MOCANU ${ }^{2}$, Valentin-Vasile BROASCĂ-MADAR ${ }^{2}$, Loredana PAZARA²,

\begin{abstract}
The healthcare associated infections (HAI) represent a significant problem for the public heath and it has a big impact on the following plans: epidemiological, clinical and economical. Also, a major importance represents the activity of monitoring and controling the infections along with a corect reporting of the cases.

The authors conducted a retrospective study in order to evaluate the number of cases of healthcare associated infections in Constanta County over a period of 5 years, observing a significant increase in HAI reporting during the study period. The most common types of infections were digestive tract infections, followed by respiratory infections, sepsis, surgical wound infections, and urinary tract infections. The departments with the best registration and reporting of healthcare-associated infections are those with a surgical profile, pediatrics, newborns, obstetrics-gynecology and intensive care unit.

Following the study, the authors find a better reporting of healthcare associated infections over the 5 years studied, which proves that health units have begun to recognize and manage them properly. This will have a major favorable impact in the prevention and identification of risk factors associated with this category of infections.
\end{abstract}

Keywords: healthcare associated infections, reporting, growth

\section{REZUMAT}

Infecțiile asociate asistenței medicale (IAAM) reprezintă o problemă de sănătate publică cu un impact deosebit in plan epidemiologic, clinic și economic, iar activitatea de supraveghere și control a acestora, alături de o raportare corectă a cazurilor, are o importanță majoră.

Autorii realizează un studiu retrospectiv cu scopul evaluării numărului de cazuri de infecții asociate asistenței medicale in județul Constanța pe o perioadă de 5 ani, observând o creștere semnificativă a raportării IAAM pe parcursul perioadei studiate. Cele mai frecvente tipuri de infecții întâlnite au fost infecțiile cu localizare digestivă, urmate de infecțiile respiratorii, sepsisul, infecțiile de plagă chirurgicală și infecțiile urinare. Secțiile cu cea mai bună înregistrare și raportare a infecțiilor asociate asistenței medicale sunt cele cu profil chirurgical, cele de pediatrie, nou-născuți, obstetrică-ginecologie și ATI. 
În urma studiului efectuat, autorii constată o mai bună raportare a infecțiilor asociate asistenței medicale de-a lungul celor 5 ani studiați, ceea ce dovedește faptul că unitățile sanitare au inceput să le recunoască și să le gestioneze corect. Acest lucru va avea un impact favorabil major în prevenția și identificarea factorilor de risc asociați acestei categorii de infecții.

Cuvinte cheie: infecții asociate asistenței medicale, raportare, creștere

\section{INTRODUCERE}

Infecțiile asociate asistenței medicale (IAAM) reprezintă una dintre problemele prioritare de sănătate publică pentru că determină o morbiditate și mortalitate crescută atât în rândul pacienților, dar și al personalului medical $[1,2]$.

Infecțiile asociate asistenței medicale sunt infecții contractate în spitale, a căror simptomatologie apare pe durata spitalizării sau după externare, în funcție de perioada de incubație și sunt determinate de microorganisme de „alertă“. Aceste microorganisme au o răspândire rapidă, sunt dificil de tratat din cauza rezistenței la antibiotice și în anumite situații pot cauza infecții severe [1-3].

Cunoașterea procesului epidemiologic condiționează eficacitatea măsurilor profilactice și de combatere a IAAM, existând anumite particularități în funcție de agentul etiologic, manifestările clinice și tipul de unitate sanitară. Prin urmare, profilaxia se adresează căilor de transmitere, având ca scop impunerea unor măsuri de neutralizare, iar combaterea IAAM se realizează prin depistarea cazurilor [4].

Supravegherea IAAM este necesară pentru acumularea de informații epidemiologice indispensabile pentru aplicarea unor măsuri eficiente de combatere, precum și pentru elaborarea unor operațiuni prevenționale fundamentate pe evaluarea riscului infecțios potențial într-un mediu aflat în relatie cu factorul uman reprezentat de pacient și personalul medical și de îngrijire $[1,5,6]$.

O raportare corectă a cazurilor de IAAM este necesară pentru a reduce riscul erorilor de înregistrare, a menține o bună funcționare a sistemului de supraveghere și pentru a avea o evaluare corectă a fenomenului, menită a permite dispunerea măsurilor optime de control $[1,5,7]$.

\section{MATERIAL ŞI METODĂ}

În cadrul acestei lucrări, am efectuat un studiu retrospectiv, analizând raportarea statistică a IAAM conform „Dării de seamă privind principalii indicatori ai cunoașterii sănătății - 10. Infecții interioare din spital” pentru perioada 01.01.2014-31.12.2018, în conformitate cu prevederile Ordinului Ministerului Sănătății nr. 919/2006 privind aprobarea normelor metodologice de înregistrare, stocare, prelucrare și transmitere a informațiilor legate de activitatea spitalului [8]. Datele necesare realizării acestui studiu au fost preluate din cadrul evidențelor statistice ale Direcției de Sănătate Publică Constanța și prelucrate în Microsoft Excel.

\section{REZULTATE}

Ca urmare a analizei evoluției numărului de cazuri de infecții asociate asistenței medicale înregistrate pe perioada celor 5 ani, în unitățile sanitare cu paturi, am observat o creștere semnificativă a numărului de cazuri raportate în fiecare an al studiului. În anul 2014, au fost raportate 20 de cazuri, în anul 2015 - 47 cazuri, în anul 2016 - 180 cazuri, în anul 2017 - 211 cazuri, iar în anul 2018 - 287 cazuri.

În anul 2014, secțiile cu cel mai mare risc de transmitere a IAAM au fost secția de pediatrie, cea de obstetrică și cea de chirurgie. Cele mai frecvente infecții au fost cele digestive, urmate de infecțiile de plagă chirurgicală (fig. 1).

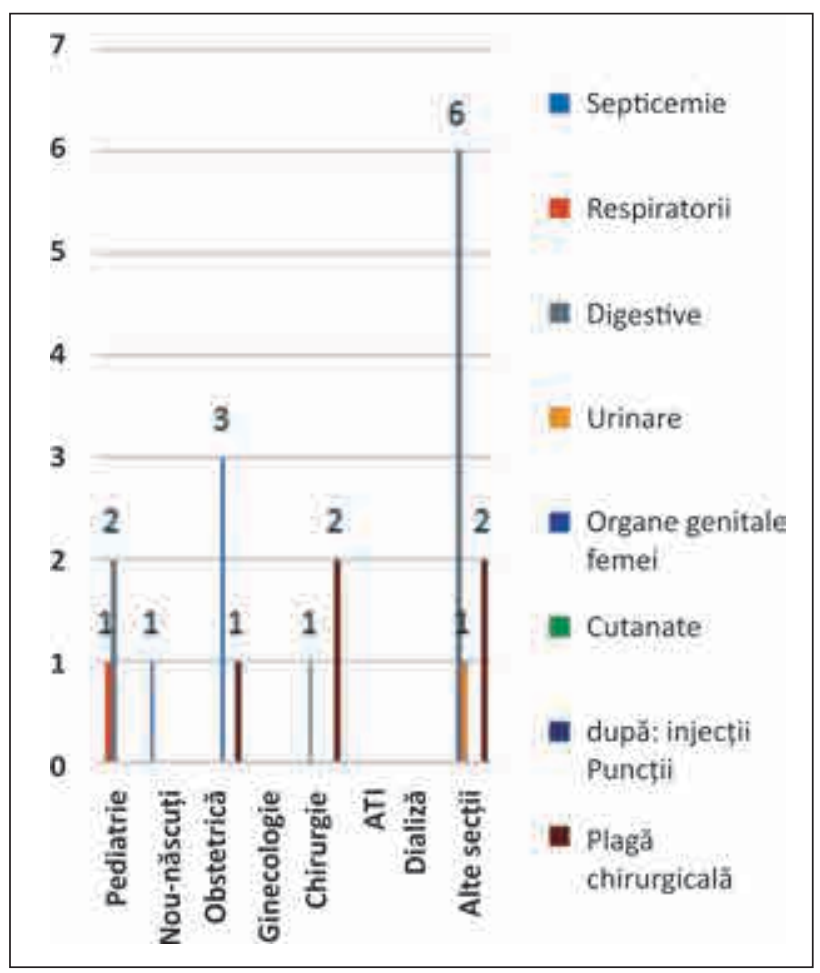

FIGURA 1. Distribuția IAAM pe secții, județul Constanța, anul 2014 
În anul 2015, s-a menținut aceeași ierarhie, secțiile de pediatrie având un total de 47 de cazuri de IAAM raportate, dintre care mai mult de $50 \%$ dintre infecții au fost de tip digestiv. Urmează secțiile de chirurgie (8 infecții, dintre care 6 sunt de tip digestiv) și cele de obstetrică (5 cazuri, dintre care 4 au fost infecții de plagă chirurgicală) (fig. 2).

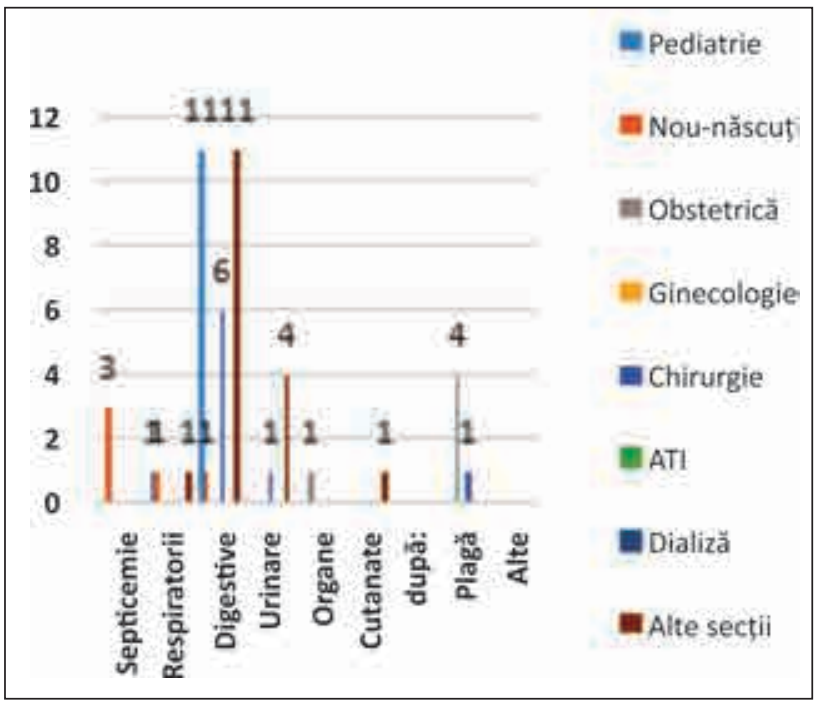

FIGURA 2. Distribuția IAAM pe secții, județul Constanța, anul 2015

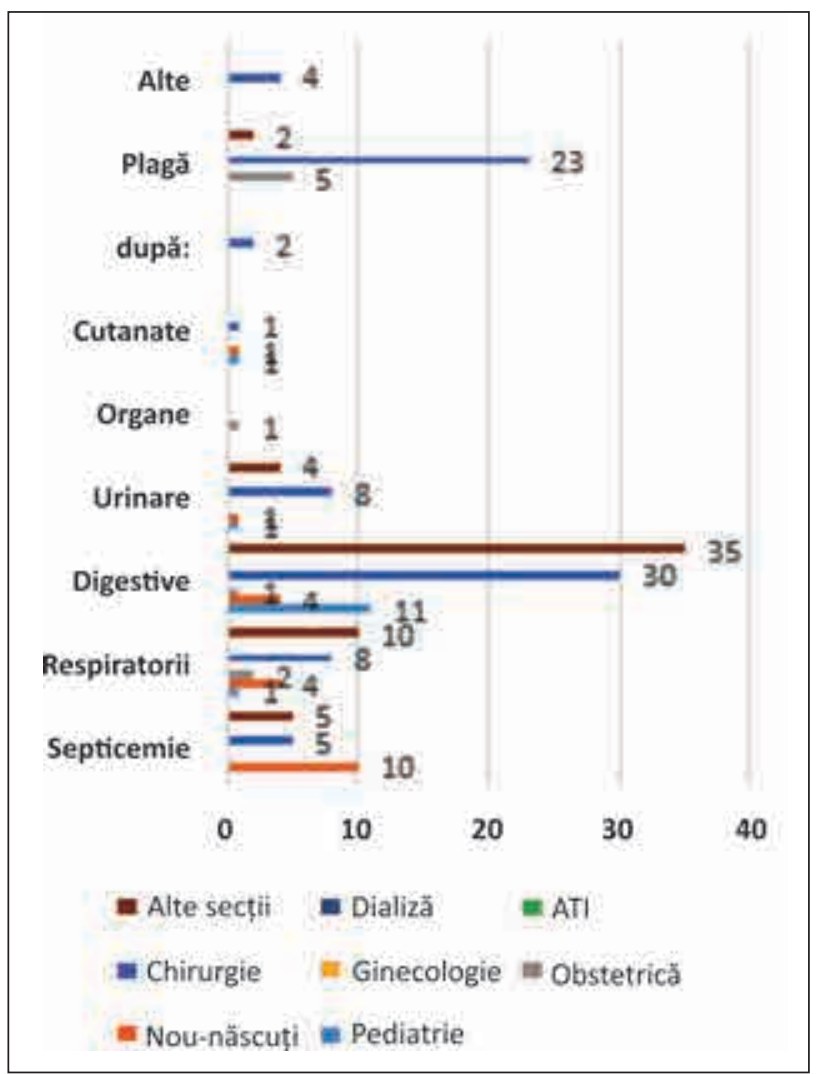

FIGURA 3. Distribuția IAAM pe secții, județul Constanța, anul 2016

În anul 2016, numărul de IAAM raportate a crescut la un total de 180 , dintre care $81 \mathrm{~s}$-au regăsit pe secțiile de chirurgie, pe secțiile de pediatrie - 14 cazuri, iar pe cele de obstetrică - 9 cazuri. Ca și în anii anteriori, pe primul loc s-au aflat infecțiile digestive - 81, urmate de cele de plagă chirurgicală -30 , respiratorii -25 , septicemie - 20 și urinare - 14 (fig. 3).

În anul 2017, se menține creșterea raportării IAAM, ajungând la 211. Secțiile de chirurgie au avut cele mai multe IAAM - 65, dintre care cel mai des întâlnite au fost IAAM digestive - 30 și de plagă chirurgicală - 14 . Secțiile de pediatrie au însumat un total de 22 de IAAM, dintre care 19 au fost de tip digestiv (fig. 4).

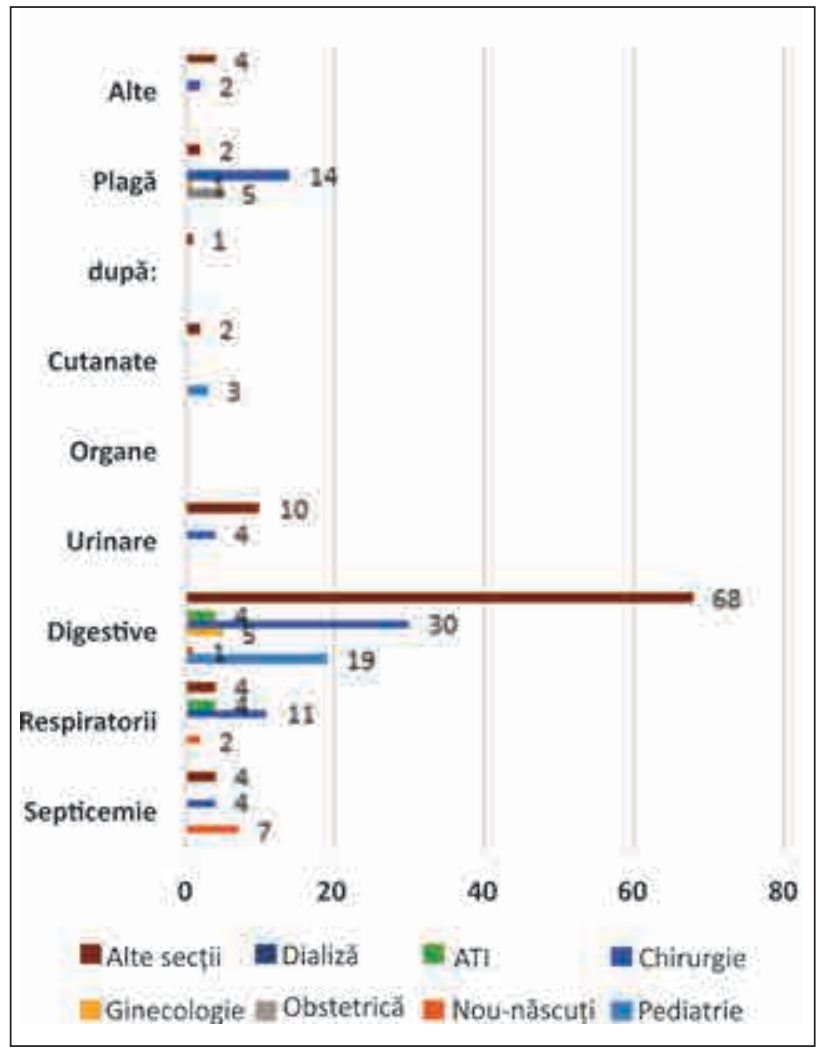

FIGURA 4. Distribuția IAAM pe secții, județul Constanța, anul 2017

În anul 2018, raportarea cazurilor s-a menținut ridicată, fiind în număr de 287, dintre care 185 au fost infecții digestive, 47 - infecții respiratorii, 25 - infecții de plagă chirurgicală și 12 - septicemie. Secțiile cu numărul cel mai ridicat de IAAM au fost următoarele: 95 de cazuri în secțiile de chirurgie, 35 de cazuri în secțiile de pediatrie, 21 de cazuri în secțiile de ATI și 12 în cele de obstetrică (fig. 5).

Se poate observa că, din totalul infecțiilor asociate asistenței medicale analizate pe cei 5 ani, în număr de 745 , cel mai des întâlnite sunt infecțiile digestive - 431, urmate de cele respiratorii -108 și septicemie -51 . Infecțiile digestive au fost determinate, în principal, de germeni greu de controlat în condițiile aglomerării din spitale (rotavirusuri în secțiile de pediatrie, Clostridium difficile în cele chirurgicale), explicând numărul important de infecții cu o prevenție aparent facilă. MRSA a predominat în infecțiile de plăgi chirurgicale (fig. 6). 


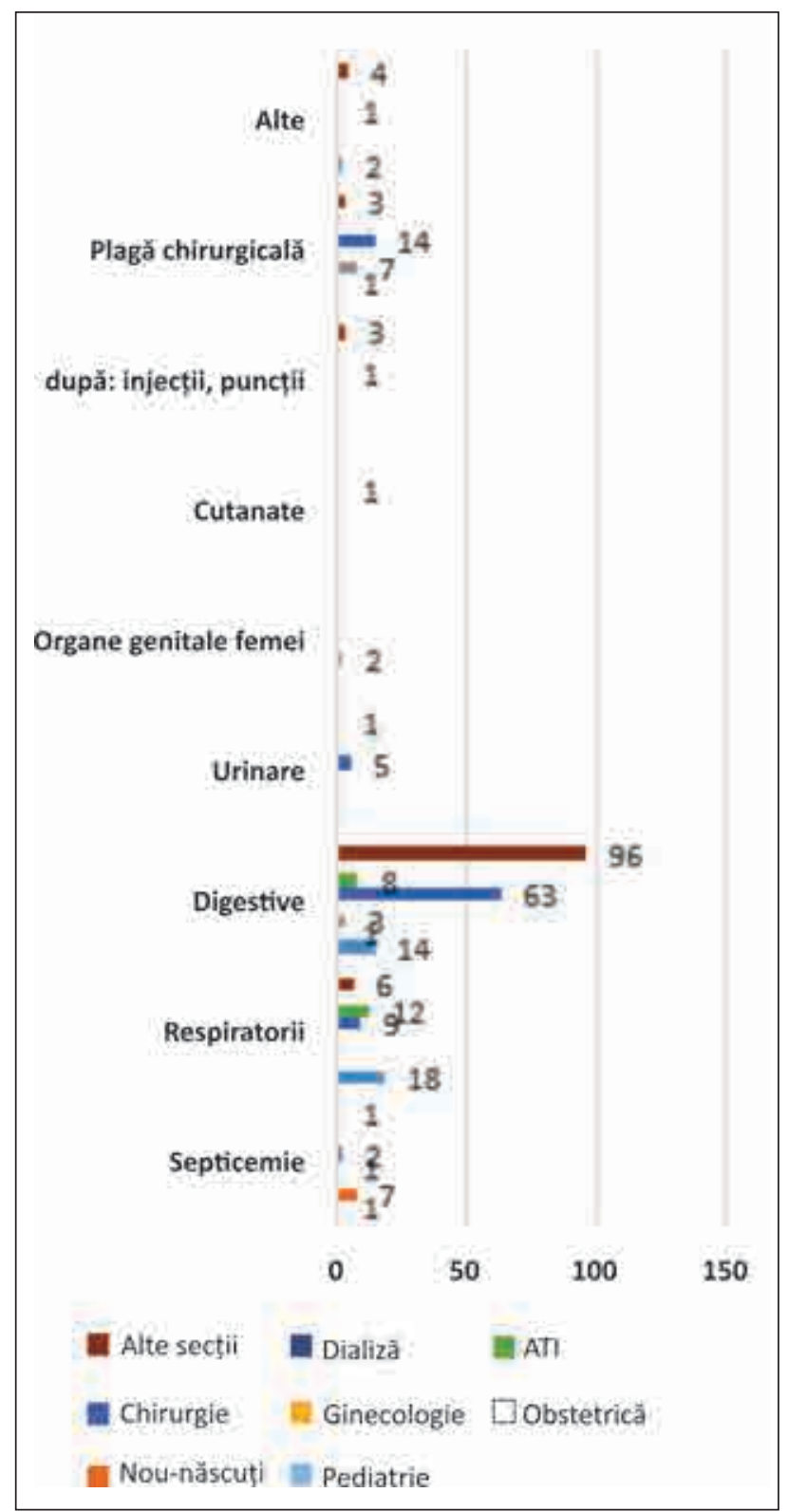

FIGURA 5. Distribuția IAAM pe secții, județul Constanța, anul 2018

\section{DISCUȚII}

Conform datelor publicate de Centrul Național de Supraveghere și Control al Bolilor Transmisibile, numărul infecțiilor asociate asistenței medicale inregistrate la nivel național a crescut progresiv în ultimii ani, ca urmare a îmbunătățirii sistemului de raportare prin im-

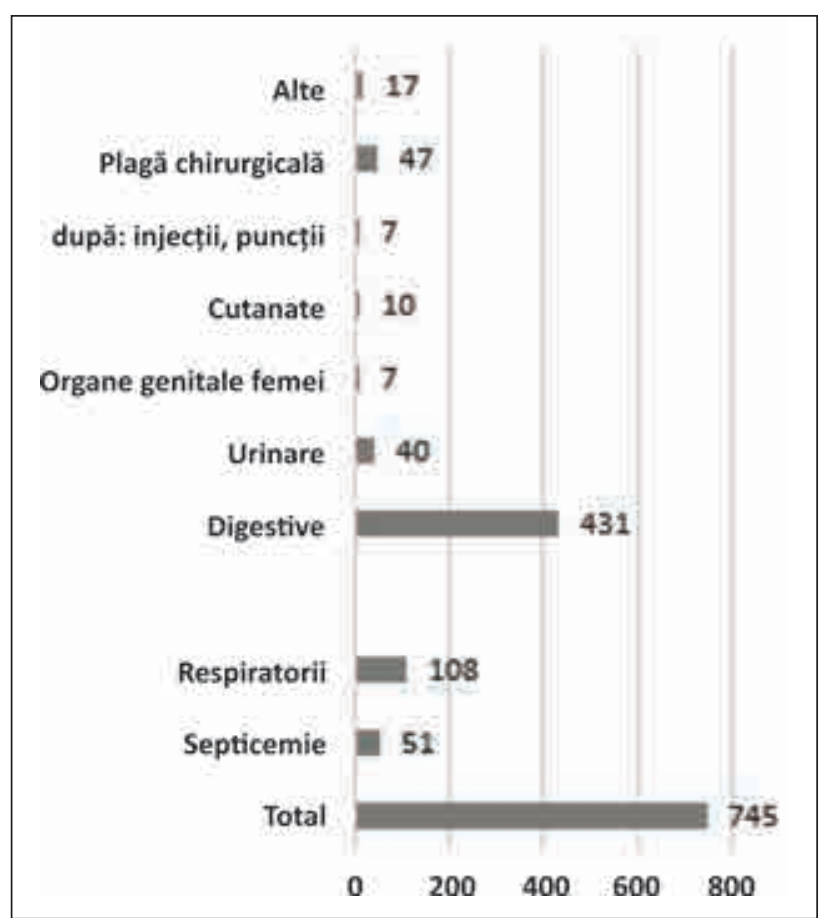

FIGURA 6. Distribuția numărului total de IAAM în funcție de tipul infecției, județul Constanța

plementarea programului informatic CaPeSaRo, fapt constatat și la nivelul județului Constanța.

Am realizat o comparație între valorile raportate pe fiecare an studiat la nivelul României și la nivelul județului nostru, date ilustrate în tabelul 1.

TABEL 1. Numărul de IAAM raportate la nivel național comparativ cu cel la nivelul județului Constanța în perioada 2014-2018 [9]

\begin{tabular}{|c|c|c|}
\hline AN & România & Constanța \\
\hline $\mathbf{2 0 1 4}$ & 10.630 & 20 \\
\hline $\mathbf{2 0 1 5}$ & 12.316 & 47 \\
\hline $\mathbf{2 0 1 6}$ & 16.175 & 180 \\
\hline $\mathbf{2 0 1 7}$ & 19.607 & 211 \\
\hline $\mathbf{2 0 1 8}$ & 20.240 & 287 \\
\hline
\end{tabular}

Se poate evidenția o ascensiune a numărului de cazuri raportate în perioada 2014-2018, mai exact, o creștere cu 90,4\% [9].

Am constatat că există aceeași ierarhie a tipurilor de IAAM ca și în cadrul județului Constanța, cele mai frecvente fiind infecțiile digestive, urmate de cele respiratorii, urinare și de plagă chirurgicală.

TABEL 2. Infecții asociate asistenței medicale raportate la nivel național în perioada 2014-2018 [9]

\begin{tabular}{|c|c|c|c|c|c|c|c|c|c|}
\hline An & $\begin{array}{c}\text { Total } \\
\text { infecții }\end{array}$ & Septicemii & Respiratorii & Digestive & Urinare & Genitale & $\begin{array}{c}\text { Plagă } \\
\text { chirurgicală }\end{array}$ & Cutanate & Alte \\
\hline $\mathbf{2 0 1 4}$ & 10.630 & 752 & 2.457 & .3022 & 1.769 & 186 & 1542 & 296 & 606 \\
\hline $\mathbf{2 0 1 5}$ & 12.316 & 959 & 2.549 & 4.074 & 1.938 & 180 & 1724 & 268 & 624 \\
\hline $\mathbf{2 0 1 6}$ & 16.175 & 1209 & 3.063 & 5.695 & 2.419 & 233 & 2276 & 455 & 825 \\
\hline $\mathbf{2 0 1 7}$ & 19.607 & 1304 & 3.549 & 8.019 & 2.568 & 181 & 2297 & 834 & 840 \\
\hline $\mathbf{2 0 1 8}$ & 20.240 & 1513 & 3.727 & 8.124 & 2.674 & 213 & 2362 & 618 & 1.009 \\
\hline
\end{tabular}


Acest trend ascendent este în concordanță cu ceea ce se întâmplă la nivel mondial.

Un recent studiu european a constatat că, anual, în Uniunea Europeană și în Spațiul Economic European, 2.609.911 noi pacienți au fost identificați ca având IAAM [10].

Centrul pentru Controlul și Prevenirea Bolilor SUA indică faptul că aproape 1,7 milioane de pacienți spitalizați dobândesc anual IAAM în timp ce sunt tratați pentru alte afecțiuni și că peste 98.000 (1 pacient din 17) mor din această cauză [11].

Potrivit Agenției pentru Cercetare și Calitate a Asistenței Medicale din SUA, IAAM sunt cele mai comune complicații datorate îngrijirilor medicale și una dintre primele 10 cauze de deces din SUA [11].

Conform unui studiu retrospectiv asemănător realizat într-un spital din Beijing, China, pe o perioadă de 5 ani, respectiv 2013-2017, autorii au relatat faptul că a existat o scădere ușoară a numărului de infecții asociate asistenței medicale în urma implementării unei baze de date electronice care măsoară incidența IAAM. De asemenea, a relevat o tendință de scădere a infecțiilor tractului respirator, o tendință de creștere a infecțiilor de cateter si a sepsisului. Rata de incidență a infecțiilor tractului urinar și a infecțiilor digestive a rămas neschimbată. Toate aceste aspecte subliniază importanța supravegherii continue și în detaliu ce stă la baza unor măsuri eficiente de prevenție și combatere a acestei categorii de infecții [12].

Nu este astfel întâmplător că, de mai mulți ani, OMS susține că igiena eficientă a mâinilor este cea mai importantă practică pentru prevenirea și controlul IAAM, care formează colonii cu microbi MDR. Această măsură ajută la reducerea morbidității și la minimizarea costurilor de îngrijire a sănătății [13,14].

\section{CONCLUZII}

În urma studiului efectuat, am constatat o creștere semnificativă a raportării IAAM de-a lungul celor 5 ani, respectiv 2014-2018, ceea ce evidențiază o preocupare tot mai mare a unităților sanitare în recunoașterea și raportarea lor pentru a putea fi gestionate corect.

Valoarea cazurilor înregistrate în perioada studiată, pe tipuri de secții și afecțiuni, se constituie într-un prim etalon la care se pot raporta viitoarele analize, care vor aborda și aprofunda etiologia cazurilor de IAAM.

Informatizarea sistemului de raportare a cazurilor de IAAM a avut un efect pozitiv în implicarea activă a personalului medical în supravegherea și controlul acestora.
Conflict of interest: none declared Financial support: none declared

\section{$\overline{\text { BIBLIOGRAFIE }}$}

1. Cepoi C, Azoicăi D. Ghid de management al infecţiilor asociate asistenţei medicale. Ediţia II. București: SC Global Management Arte, 2017.

2. Șerban IG, Rugină S. Experienţe europene în supravegherea şi controlul infecţilor nosocomiale. Conferinţă Naţională cu participare internaţională, Braşov, 31 martie-2 aprilie 2011. Ed. Ecran Magazin SRL, 2011;11-12.

3. Hallam C, Marincaș R. "Primum non nocere" - În primul rând să nu faci rău recomandări de prevenire a infecţiilor asociate îngrijirilor medicale, ed II. Cluj-Napoca: Caiete silvane, 2019

4. Măgureanu E, Busuioc C. Ghid de epidemiologie practică, profilaxia și combaterea bolilor transmisibile. București: Editura Medicală, 1985.

5. Cepoi V. Managementul riscurilor clinice, ANCSM, 2019. Available at: https://www. dreptulmedical.ro/wp-content/ uploads/2018/02/Managementul-riscurilorclinice-Vasile-Cepoi.pdf.

6. Prelipcean M, Fochi M. Evaluarea riscului infecţios în cursul manevrelor medico- chirurgicale invazive, ANCSM, 2017. Available at: https://sanatateromania.ro/ wp-content/uploads/2017/04/

Prelipcean_S.M._Fochi_M_-_Evaluarea_ riscului_infectios.pdf.

7. Ordinul Ministerului Sănătăţii 1101/2016 privind aprobarea normelor metodologice de prevenire şi combatere a infecţiilor asociate asistenţei medicale.

8. Ordinul Ministerului Sănătăţii 919/2006 privind aprobarea normelor metodologice de înregistrare, stocare, prelucrare şi transmitere a informatiilor legate de activitatea spitalului.

9. Consumul de antibiotice, Rezistenţa microbiană și infecţii asociate asistenţei medicale în România - 2018 (cnscbt.ro). Available at: http://www.cnscbt.ro/index.php/ analiza-date-supraveghere/infectiinosocomiale-1/2025-consumul-deantibiotice-rezistenta-microbiana-si-infectiileasociate-asistentei-medicale-romania-2018/ file.

10. Magill SS, Wilson LE, Thompson DL, Ray SM, Nadle J, Lynfield R, Janelle SJ, Kainer MA, Greissman S, Dumyati G, Beldavs ZG,
Edwards JR; Emerging Infections Program Hospital Prevalence Survey Team. Reduction in the Prevalence of HealthcareAssociated Infections in U.S. Acute Care Hospitals, 2015 vs 2011. Open Forum Infect Dis. 2017 Oct 4;4(Suppl 1):S49.

11. Haque M, Sartelli M, McKimm J, Abu Bakar M. Health care-associated infections - an overview. Infect Drug Resist. 2018 Nov 15;11:2321-2333.

12. Zhang Y, Du M, Johnston JM et al. Incidence of healthcare-associated infections in a tertiary hospital in Beijing, China: results from a real-time surveillance system. Antimicrob Resist Infect Control. 2019;8:145.

13. Voss A, Widmer AF. No time for handwashing!? Handwashing versus alcoholic rub: can we afford $100 \%$ compliance? Infect Control Hosp Epidemiol. 1997 Mar;18(3):205-8.

14. Widmer AF, Conzelmann M, Tomic M, Frei $\mathrm{R}$, Stranden AM. Introducing alcohol-based hand rub for hand hygiene: the critical need for training. Infect Control Hosp Epidemiol. 2007 Jan;28(1):50-4. 